\title{
Neutron Radiography Reactor Reactivity- Focused Lessons Learned
}

Eric C. Woolstenhulme

Randal G. Damiana

Kenneth A. Schreck

Ann Marie Phillips

November 2010

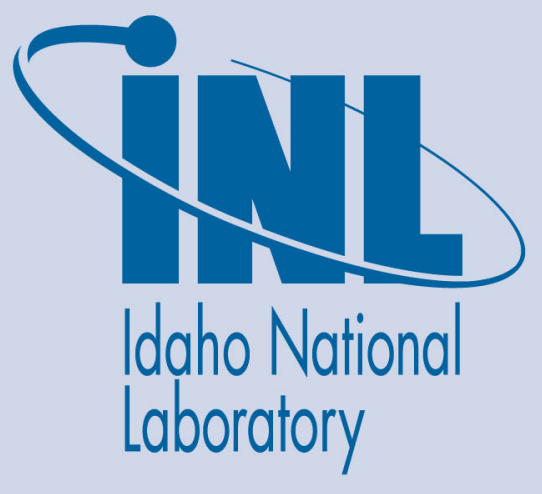

The INL is a U.S. Department of Energy National Laboratory operated by Battelle Energy Alliance 


\section{DISCLAIMER}

This information was prepared as an account of work sponsored by an agency of the U.S. Government. Neither the U.S. Government nor any agency thereof, nor any of their employees, makes any warranty, expressed or implied, or assumes any legal liability or responsibility for the accuracy, completeness, or usefulness, of any information, apparatus, product, or process disclosed, or represents that its use would not infringe privately owned rights. References herein to any specific commercial product, process, or service by trade name, trade mark, manufacturer, or otherwise, does not necessarily constitute or imply its endorsement, recommendation, or favoring by the U.S. Government or any agency thereof. The views and opinions of authors expressed herein do not necessarily state or reflect those of the U.S. Government or any agency thereof. 


\title{
Neutron Radiography Reactor Reactivity - Focused Lessons Learned
}

\author{
Eric C. Woolstenhulme \\ Randal G. Damiana \\ Kenneth A. Schreck \\ Ann Marie Phillips
}

November 2010

Idaho National Laboratory Idaho Falls, Idaho 83415

http://www.inl.gov

\author{
Prepared for the
}

U.S. Department of Energy

Office of National Nuclear Security Administration

Under DOE Idaho Operations Office

Contract DE-AC07-05ID14517 



\begin{abstract}
As part of the Global Threat Reduction Initiative, the Neutron Radiography Reactor (NRAD) at Idaho National Laboratory was converted from using highly enriched uranium (HEU) to low-enriched uranium (LEU) fuel. After the conversion, NRAD resumed operations and is meeting current customer commitments. Radiography image quality and the number of images that can be produced in a given time frame match pre-conversion capabilities. However, following the conversion, NRAD's excess reactivity with the LEU fuel was less than it had been with the HEU fuel. Although some differences between model predictions and actual performance are to be expected, the lack of flexibility in NRAD's safety documentation prevented adjusting the reactivity by adding more fuel, until the safety documentation could be modified. To aid future reactor conversions, a reactivity-focused lessons learned workshop was held. This report summarizes the findings of the lessons learned workshop and addresses specific questions posed by the Department of Energy regarding NRAD's conversion and reactivity.
\end{abstract}




\section{CONTENTS}

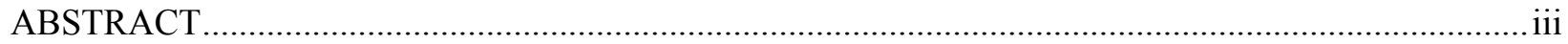

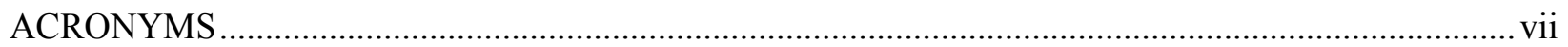

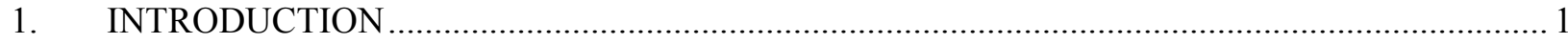

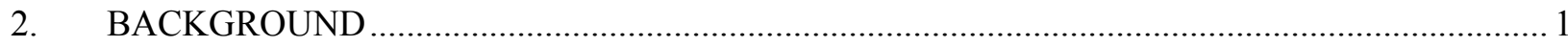

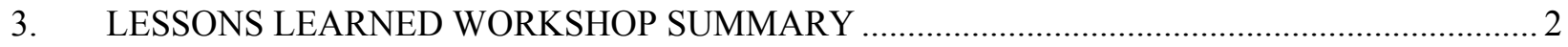

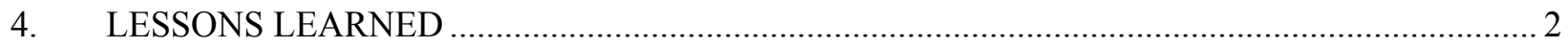

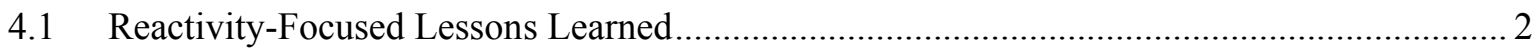

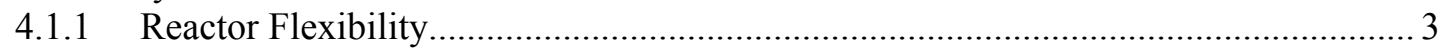

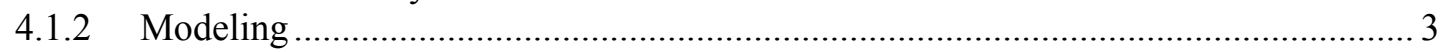

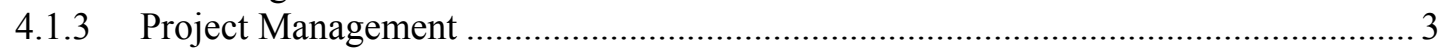

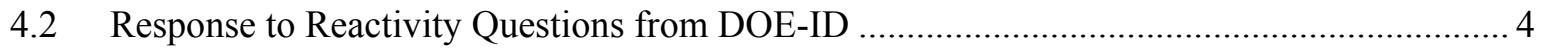

4.3 Response to NRAD Conversion Technical Details Request from DOE-ID ........................... 5

4.3.1 NRAD Conversion Technical Details .................................................................... 5

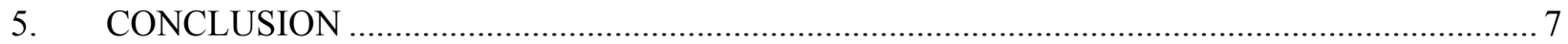




\section{ACRONYMS}

$\mathrm{CCN} \quad$ Correspondence Control Number

DOE U.S. Department of Energy

DOE-ID U.S. Department of Energy Idaho Operations Office

GA General Atomics

GTRI Global Threat Reduction Initiative

HEU highly enriched uranium

INL Idaho National Laboratory

LEU low enriched uranium

MCNP Monte Carlo N-Particle Transport Code

NNSA National Nuclear Security Administration

NRAD Neutron Radiography (reactor)

PRNC Puerto Rico Nuclear Center

SAR Safety Analysis Report

TRIGA Training, Research, Isotopes, General Atomics 


\section{Neutron Radiography Reactor Reactivity-Focused Lessons Learned}

\section{INTRODUCTION}

To reduce the amount of weapons-grade nuclear material worldwide, the National Nuclear Security Administration (NNSA), as part of the Global Threat Reduction Initiative (GTRI), has established a program to convert research and test reactors from using highly enriched uranium (HEU) to low enriched uranium (LEU) fuel to reduce proliferation risks. As part of this program, the Neutron Radiography Reactor (NRAD) at Idaho National Laboratory (INL) was converted from HEU to LEU fuel. NRAD is a Training, Research, Isotope Production, General Atomics (TRIGA) reactor.

\section{BACKGROUND}

As part of NRAD's conversion process, General Atomics (GA) performed neutronics and thermal/hydraulic analyses to estimate NRAD's performance with the LEU core. Analysis results indicated NRAD performance with LEU would be similar to the HEU performance and that initial criticality would occur in the 52+/- 4 element range. During startup with the LEU core, NRAD's initial criticality was achieved with 56 elements. After adding the remaining four elements to complete the 60 element core, NRAD's excess reactivity was less than predicted by the model and less than it had been with the HEU core. Model refinements were made, reducing the model predicted reactivity and bringing the prediction closer to actual measured reactivity. As is typical for TRIGA reactors, a bias was applied to the model to align it with actual measured data. Although some differences between model predictions and actual performance are to be expected, the lack of flexibility in NRAD's safety documentation prevented adjusting the reactivity by adding more fuel, until the safety documentation could be modified. NRAD can perform its mission and neither radiography nor current customer commitments are affected, but the reactor performance capability with LEU is reduced compared to HEU. The reactor cannot run as many consecutive days and experiment capabilities are reduced. To restore NRAD to pre-conversion performance capabilities, four more fuel elements and four graphite elements will be added to the core. A reactivity-focused lessons learned workshop was held to capture lessons learned that may aid future conversions. Consistent with the agenda and workshop purpose, the workshop focused on responding to the questions presented by DOE-ID for lessons learned and also on the reactivity lessons learned from the team participant's point of view. The workshop attendees included all participating team members and their representatives. This report summarizes the findings of the lessons learned workshop and addresses the specific questions posed by the Department of Energy (DOE) regarding NRAD's conversion and reactivity. In addition, Section 4.3 of this report contains NRAD conversion technical details requested by DOE that provide background information for the lessons learned. 


\section{LESSONS LEARNED WORKSHOP SUMMARY}

A reactivity-focused lessons learned workshop for NRAD was held October 20, 2010 at the Willow Creek Building in Idaho Falls, Idaho. This interim lessons learned workshop focused only on reactivity issues. The final project lessons learned will be issued at the completion of the project after fuel addition is accomplished. The workshop attendees were:

\begin{tabular}{|l|l|}
\hline Dana Hewit, INL & Ken Schreck, INL \\
\hline Eric Woolstenhulme, INL & Ning Zhang, INL \\
\hline Randy Damiana, INL & Leland Montierth, INL \\
\hline Ann Marie Phillips, INL & Steve Sorrell, DOE-ID \\
\hline John Bess, INL & Kermit Bunde, DOE-ID \\
\hline Wade Capson, INL & John Bolin, GA \\
\hline Tom Maddock, INL & Chris Ellis, GA \\
\hline Andrew Smolinski, INL & \\
\hline
\end{tabular}

The workshop followed this agenda:

8:00 Welcome

8:10 Introductions, Logistics, Agenda

8:20 Respond to Questions posed by DOE-ID

10:00 Break

10:20 Identify Reactivity-Focused Lessons Learned

11:45 Summarize the Lessons Learned

12:00 Discuss the Labeling of GA Documents, Discuss the NRAD Models

12:45 Adjourn

\section{LESSONS LEARNED}

This lesson learned was unique in the fact that it focused only on the reactivity aspects of the NRAD conversion. This report addresses three basic areas of discussion from the workshop. First, many aspects of the conversion project were discussed by the group. The issues from these discussions were captured during the workshop and are listed in following Section 4.1. The group also focused on supplying answers to the questions included in the Department of Energy, Idaho Operations office letter, Correspondence Control Number (CCN) 221845. The third section provides the NRAD conversion technical details requested in CCN 221845.

\subsection{Reactivity-Focused Lessons Learned}

The material presented in this section discusses the basic lessons learned topics that were introduced during the workshop. A more complete narrative of these topics will be provided in the final lessons learned report. This material was discussed at this early stage in an effort to provide insight to the upcoming High Performance reactor conversions in avoiding similar difficulties. 


\subsubsection{Reactor Flexibility}

- Rather than requiring a specific core configuration, it would have been advantageous to have changed the safety basis to focus on limiting core excess reactivity. This approach would allow core fuel configuration and loading flexibility.

- Allowing flexibility in the Safety Analysis Report (SAR) to vary the last few clusters during the approach to critical would have allowed for a better understanding of the core neutronics and testing. For example, the clusters could have been made up of less than four fuel elements and then contain dummy elements or reflector elements to better refine the reactor startup.

- Identifying specific reactor performance project risks such as reactivity might have allowed the conversion project team to make contingency plans to mitigate those risks.

\subsubsection{Modeling}

- Although there are always uncertainties in reactor modeling, some steps could have been taken to reduce the uncertainty in portions of the model. To verify the model assumptions about the non-fuel portions of the core, experiments could have been performed to measure their affect on core reactivity. This would have provided data to confirm that the model accurately reflected their affect on reactivity.

- Another potential step would have been to model the existing HEU core to confirm that the new LEU model was accurate. However, this was not possible because NRAD was fueled with partially burned HEU from the decommissioned Puerto Rican Nuclear Center (PRNC) reactor, and accurate burn-up data for the NRAD HEU was not known.

- Since the LEU was expected to be a one-for-one replacement for the HEU, the current HEU core reactivity could have been compared to the model prediction for LEU core reactivity, to validate the model prediction.

- Anticipating that the Hot to Cold swing (difference in reactivity between the reactor at full power versus cold critical startup) for HEU and LEU will be different would have provided insight into the expected differences in reactivity.

- Benchmarking efforts should be continued, along with other ongoing efforts to continually refine the neutron cross section library. Efforts should also persist to ensure the latest available updates to the neutron cross section library are being used to improve modeling accuracy.

- Indications of LEU core performance could have been obtained by adding one LEU element (or cluster) and assessing the impact on HEU core performance before converting the entire core. Further, the addition of a single LEU element to the HEU core could have been modeled and compared to the measured data, providing valuable information about the model accuracy.

\subsubsection{Project Management}

- Realistic project schedules that take into account site resources and approval cycles need to be made. The project should also have the ability to change the schedule based upon project findings (model issues etc.) as the project matures.

- The NRAD would have benefited by increasing its TRIGA reactor physics capabilities prior to the conversion. NRAD needs to work to assign and maintain cognizant reactor physics engineers at the NRAD reactor. One of the engineers' responsibilities would be to gain and maintain the "tribal" knowledge and historic data for the reactor. 


\subsection{Response to Reactivity Questions from DOE-ID}

The lessons learned workshop addressed the seven questions included in the DOE Idaho Operations Office (DOE-ID) letter, CCN 221845, "Request for Lessons Learned from the Neutron Radiography Reactor High Enriched Uranium to Low Enriched Uranium Conversion (IS-10-043)" dated August 19, 2010. The discussions are summarized below:

1. What were the indicators available to the LEU conversion team that predicted that NRAD performance may not have been as expected?

Both INL and the GA model results using the latest data before start-up indicated the predicted excess reactivity would be acceptable. A performance issue was noted when the reactor went critical at the upper end of the predicted fuel element count (56 versus 48). Comparing models and performance data from previous TRIGA reactor conversions indicated that model predictions of reactivity have large uncertainties. However, since some models over predicted while others under predicted reactivity, this would not have provided enough information to prevent NRAD's low reactivity.

2. What could have been done to increase confidence in the core reload final parameters (i.e., Monte Carlo N-Particle Transport Code [MCNP] or other computer code predictions)?

The confidence in the modeling was perhaps too high, which did not direct the team to question the model or consider alternatives/mitigations if the reactivity was lower than predicted. Other TRIGA conversions required changes in their predicted core configurations. More attention to this detail would have resulted in allowing more flexibility in the NRAD LEU core loading.

The NRAD HEU fuel was obtained from the decommissioned PRNC reactor. The PRNC reactor was used as a baseline for the HEU fuel since HEU fuel was in a "fresh" state for that core. The existing NRAD HEU core could have been modeled. However, because the exact burn-up of the fuel was not known, there would have been large uncertainties in the results. The recently started Romanian Reactor could have been benchmarked prior to the NRAD conversion to refine neutron cross section data. Benchmark data for TRIGA reactors is limited, so continuing to benchmark will improve future modeling efforts.

3. Are there other issues (besides excess reactivity) that could affect conduct of operations, engineering or maintenance, or customer requirements?

There is a potential that until more fuel can be added to the core, the reactor may not achieve full power after extended operation cycles because of poison buildup in the fuel. Currently the operational demand does not have extended operation cycles scheduled. Additional engineering, maintenance, or operational issues are not anticipated. All current customer requirements can be met.

4. What lessons learned should be applied to the future refueling of high-performance reactors where core configuration (e.g., number of fuel elements, core materials, reflectors) cannot be easily modified?

a. Safety documentation should allow flexibility of the fuel and core configuration so necessary adjustments can be made to obtain the required excess reactivity. This flexibility may include a core with a mixture of fueled and un-fueled elements, fuel elements that have plates with various fuel concentration, zone loading or poison content.

b. Adding one LEU element (or cluster) to the HEU core and assessing the performance prior to converting the entire core could provide beneficial data.

c. Model and do experiments on the existing non-fuel portions of the core to verify model assumptions.

d. Develop a realistic schedule and allow for adjustments as issues arise. 
e. Anticipate that the Hot to Cold swing (difference in reactivity between the reactor at full power versus cold critical startup) for HEU and LEU will be different.

5. How was the NRAD LEU reload benchmarked prior to the conversion?

A benchmark was performed using the Puerto Rican Cold Clean Core because accurate burn-up data for the NRAD HEU was not known. The NRAD HEU core used fewer elements than the Puerto Rican core. Information on where the NRAD HEU elements were located in the Puerto Rican core was not available.

6. What prior communications occurred with the operating organization regarding possible deviations from planned performance?

Early on and throughout the project, GA had discussions with INL about the conversion, including possible reactivity performance deviations. As a result of the discussions a range for the number of elements needed to establish criticality was built into the start-up plan.

7. Discuss the comparison of the various results including an explanation of any significant differences that could affect normal operation and accident analyses.

a. Normal Operations

Based on current operational demand, there is no impact to NRAD operations. Radiography image quality and the time required to produce a single image matches pre-conversion capabilities. Core excess reactivity and xenon build-up limit the number of days for consecutive operations. In-core experiments that have a negative reactivity effect on the core are limited. Addition of fuel elements will restore the reactor to its previous HEU capability.

b. Accident Analyses

Calculations for the accident analyses are conservative. There was no impact on the accident analyses. All accidents are bounded within the analyses. Addition of fuel will be bounded by the current criticality and accident analyses. Low excess reactivity poses no safety issues.

Adding more fuel (from 60 to 64 elements) increases the safety margin because it reduces the power per element, and therefore the fuel temperature in the individual elements will be lower.

\subsection{Response to NRAD Conversion Technical Details Request from DOE-ID}

The following information provides background information for the lessons learned and addresses the request for NRAD conversion technical details included in the DOE-ID letter, CCN 221845, "Request for Lessons Learned from the Neutron Radiography Reactor High Enriched Uranium to Low-Enriched Uranium Conversion (IS-10-043)," dated August 19, 2010.

\subsubsection{NRAD Conversion Technical Details}

1. Critical Mass

Measurement with HEU: 61 partially burned HEU fuel elements were installed at NRAD initial criticality.

Measurement with LEU: 56 LEU fuel elements with total of 8,285 grams of U- 235 .

2. Comparison with calculations for LEU and if available, HEU excess reactivity

Measurement with HEU: HEU core configuration at shutdown June 2009, Cold Clean Excess reactivity $\$ 1.56$. Hot Excess Reactivity $\$ 0.93$.

Measurement with LEU: LEU operational core configuration April 2010, Cold Excess Reactivity \$1.19. Hot Excess Reactivity \$0.17. 
3. Comparisons with calculations for LEU and if available HEU Control Rod calibrations

Measurement with HEU: Shim 1 \$2.82, Shim 2 \$2.85, Regulating Rod \$2.46

Measurement with LEU: Shim 1 \$2.83, Shim 2 \$2.91, Regulating Rod \$2.47

4. Reactor Power Calibration

Methods and measurements that ensure operation within license limits and comparison between HEU and LEU nuclear instrumentation set points, detector positions, and detector output:

Methods and measurement techniques did not change between the HEU and LEU cores. A heat balance is performed using primary system flows and temperatures. The resulting thermal output is compared to the nuclear instrument indication. During the initial approach to full power, the power calibration was performed at 100, 200, and 250 kilowatts. Minor adjustments to the detector gain settings were performed to match indicated power with the calculated thermal power. Detector locations and height relative to the core were not changed between the HEU core and the LEU core.

5. Shutdown Margin

Measured with HEU: The total control rod worth of the HEU core prior to conversion was $\$ 8.13$, which yields a shutdown margin of $\$ 2.31$ with the most reactive rod (Shim Rod 2) fully withdrawn, while the second-most reactive rod (Shim Rod 1) was half-way withdrawn.

Measured with LEU: The total control rod worth of the reactor is $\$ 8.21$, which yields a shutdown margin of $\$ 2.71$ with the most reactive rod (Shim Rod 2) fully withdrawn, while the second-most reactive rod (Shim Rod 1) was half-way withdrawn.

6. Thermal Neutron Flux Distribution

Measurements of the core and measured experimental facilities (to the extent available) with HEU and LEU and comparisons for LEU and if available, HEU.

The in-core flux distribution and in-core experiment facility flux have not been measured for the NRAD LEU core. Flux distribution and in-core experiment location flux measurements are planned following the addition of more fuel elements since this action is expected to change the profile from the HEU distribution.

A flux spectrum measurement at the east radiography beam position has been performed for the LEU core. The flux spectrum at the east beam has not changed for the LEU core as compared to the same experiment performed for the HEU core.

7. Reactor Physics Measurements

Results of determination of LEU effective delayed neutron fraction, temperature coefficient, and void coefficient to the extent measurements are possible and comparison with calculations and available HEU core measurements.

Effective delayed neutron fraction, temperature coefficient, and void coefficient have not been measured for the LEU core.

Reactivity loss as a function of power escalation and fuel temperature change was monitored. The loss of reactivity and comparison between the HEU and LEU core is provided in Item 2 above. One reason for the difference between the reactivity loss cold to hot on the LEU core as compared to the HEU core is that the fuel meat to clad gap is slightly larger for the LEU fuel. This larger gap is to aid in the fabrication of the LEU fuel elements and was accounted for in the LEU fuel element thermal hydraulic analysis. The larger gap does result in a slightly higher fuel temperature on the LEU fuel element for a given power. Since the TRIGA fuel contains Erbium poison, which has a higher cross 
section for absorption at higher fuel temperatures, the reactivity loss as power and fuel temperature are escalated on the LEU fuel is greater.

8. Initial LEU Core Loading

Measurements made during initial loading of the LEU fuel, presenting subcritical multiplication measurements, predictions of multiplication for the next fuel additions, and prediction and verification of final criticality conditions.

The requested data is available in the Startup report for the NRAD Reactor, 911195 Revision 0, dated October 4, 2010.

9. Primary Coolant Measurements

Results of any primary coolant water sample measurements for fission product activity taken during the first 30 days of LEU operation.

NRAD primary coolant water is sampled weekly for gross alpha and gross beta activity. Isotopic analysis is not performed. During the first month of LEU operation Gross Alpha activity was less than 4.7E-8 micro curies per milliliter and Gross Beta activity was $4.1 \mathrm{E}-7$ micro curies per milliliter. This activity is comparable to the values measured with the HEU core installed.

\section{CONCLUSION}

Under the GTRI program, the NRAD TRIGA reactor at INL was converted from HEU to LEU fuel. Following the conversion, the reactor resumed operations and can meet requirements with the current operational demand. However, NRAD's excess reactivity with the LEU fuel was less than it had been with the HEU fuel, limiting the number of days of consecutive operations and in-core experiment capabilities. NRAD will be restored to HEU performance capabilities by adding four fuel elements. lessons learned captured in this report are intended to assist upcoming reactors in converting from HEU to LEU. 